\title{
UM ESTUDO SOBRE DEFINIÇÕES DE COMPORTAMENTO
}

\author{
A STUDY ON DEFINITIONS OF BEHAVIOR \\ Definições de Comportamento \\ FILIPE LAZZERI \\ UNIVERSIDADE DE SÃo PAULO
}

\begin{abstract}
RESUMO
Neste trabalho, eu: (1) distingo e caracterizo alguns diferentes sentidos da noção de comportamento, com ênfase naquele de comportamento enquanto ocorrência de uma ação ou reação de um organismo; (2) identifico os tipos de definição possivelmente adequados para a noção tomada em tal sentido e para propósitos que podemos chamar de teóricos; (3) apresento uma lista de desideratos para os tipos de definição delimitados; (4) faço um exame crítico de várias (nomeadamente, doze) definições de comportamento - mais especificamente, definições com aquele sentido do conceito como definiendum - encontradas na literatura científica e filosófica; e (5) proponho uma versão modificada de duas delas.

Palavras-chave: comportamento; definições de comportamento; definições; teleologia; ação; análise conceitual.
\end{abstract}

\begin{abstract}
In this paper, I attempt to: (1) distinguish and clarify some different senses of the notion of behavior, with emphasis upon that of behavior as the occurrence of an organism's action or reaction; (2) identify the types of definition possibly suitable for the notion taken in this sense and for theoretical proposals; (3) devise a list of desiderata for the types of definition picked out; (4) make a critical survey of several (to wit, twelve) definitions of behavior - more specifically, definitions that have that sense of the concept as definiendum - found in the scientific and philosophical literature; and (5) suggest a modified version of two of them.

Keywords: behavior; definitions of behavior; definitions; teleology; action; conceptual analysis.
\end{abstract}

Este trabalho foi realizado com apoio de bolsa de doutorado concedida ao autor pela Fundação de Amparo à Pesquisa do Estado de São Paulo (FAPESP), \# 12/00059-2; e corresponde a uma versão enxuta do (a princípio) Capítulo 3 (também com o título 'Um estudo sobre definições de comportamento') de sua Tese de Doutorado, a ser defendida no começo de 2015 no Programa de Pós-Graduação em Filosofia da Universidade de São Paulo. Uma versão em inglês ainda mais sucinta do capítulo, mas que contém alguns elementos diferentes do presente trabalho, será publicada como Lazzeri (no prelo 1). O autor agradece de modo especial a Caetano E. Plastino, Maria Helena L. Hunziker e Osvaldo Pessoa Jr., pelos comentários a uma versão preliminar do trabalho. O conteúdo, no entanto, é de responsabilidade apenas do autor. Correspondência pode ser enviada para e-mail: filipelazzeri@gmail.com 
UM ESTUDO SOBRE DEFINIÇÕES DE COMPORTAMENTO

Há múltiplas definições de comportamento na literatura científica e filosófica (algumas delas sustentadas argumentativamente, mas outras apenas afirmadas). Quais dentre essas definições se mostram, se é que alguma delas, suficientemente plausíveis? Neste trabalho, procuro contribuir para uma resposta razoável a essa questão. Especificamente, nele eu: (1) distingo e caracterizo alguns diferentes sentidos da noção de comportamento, com ênfase naquele de comportamento enquanto ocorrência de uma ação ou reação de um organismo; (2) identifico os tipos de definição possivelmente adequados para a noção tomada em tal sentido e para propósitos que podemos chamar de teóricos; (3) apresento uma lista de desideratos para os tipos de definição delimitados; (4) faço um exame crítico de várias definições de comportamento - mais especificamente, definições com aquele sentido do conceito como definiendum encontradas na literatura científica e filosófica; e (5) proponho uma versão modificada de duas delas. O método que adoto para tanto é predominantemente o de análise conceitual. O trabalho está estruturado na respectiva ordem de objetivos.

\section{SENTIDOS DA NOÇÃO DE COMPORTAMENTO E ALGUMAS DE SUAS NUANÇAS}

A noção de comportamento possui várias acepções, dentre as quais: (i) comportamento como ocorrência de uma ação ou reação de um organismo; (ii) comportamento como padrão ou classe; (iii) comportamento de grupo; e (iv) comportamento como mudança ou movimento de um objeto (Lazzeri, 2014). As definições em pauta neste trabalho têm como definiendum, em geral, o conceito na acepção (i). A seguir, procuro distinguir algumas nuanças mínimas dessas diferentes acepções, com ênfase em (i) (distinguirei ainda outras na seção 3), ou seja, explicitar algumas regras que governam os usos típicos da noção, esmiuçando tipos de inferências aos quais esses usos estão associados e tipos de inferências com os quais contrastam. Embora esta seção tenha um propósito associado à busca pela determinação de quais seriam definições plausíveis de comportamento, não corresponde, por si própria, a uma resposta à questão inicial.

\section{(i) Comportamentoenquanto ocorrência de uma} ação ou reação de um organismo. Comportamento, nessa acepção, é algo frequentemente chamado também de resposta, em análise do comportamento, psicologia experimental de modo mais geral e áreas afins. Trata-se de algo emitido ou realizado por (tipicamente) um organismo, em um momento e um local específicos ${ }^{1}$. Essa acepção do conceito abrange desde coisas realizadas de maneira relativamente espontânea e flexível, como uma pessoa erguer o braço para fazer uma pergunta ou um gato abrir a porta de um recinto para dele sair; até coisas realizadas de modo relativamente automatizado e rígido, como uma pessoa afastar a mão de uma superfície abrasante ao tocá-la ou um coelho piscar o olho frente a uma rajada de vento (que são, a princípio, ocorrências de reflexos incondicionados). Os últimos casos (os quais podemos chamar de reações), diferentemente dos primeiros (os quais podemos chamar de ações), são fenômenos cuja probabilidade é relativamente alta, dada a presença mudança no ambiente ao qual os padrões dos quais são casos estão associados ${ }^{2}$.

$\mathrm{Na}$ medida em que são fenômenos emitidos ou realizados pelo organismo, comportamentos, nessa acepção, contrastam com, dentre outras coisas: (1) estados do organismo, como, por exemplo, humores (e.g., estar tranquilo, estar triste, estar radiante) e apetites (e.g., estar com fome, estar com sede), posto que estados não são o tipo de coisa que um organismo realize (cf. Kenny 1963/2003, p. 120ss; White 1968, p. 1-3); (2) coisas que correspondem à produção de um resultado incidental pelo organismo, como, por exemplo, os casos típicos de um organismo atrair um predador, produzir sombras, movimentar ar no ambiente, esmagar uma grama, etc. (cf., e.g., Wright 1976); e (3) coisas que the acontecem por inteira

\footnotetext{
Apesar de falar, aqui, em fenômenos do âmbito dos organismos - por esses sistemas serem aqueles que tipicamente exibem comportamentos em tal acepção da noção -, deixo em aberto se outros tipos de sistemas, tais como robôs e artefatos, podem exibir comportamentos nessa acepção.

2 Por vezes chamamos de reações alguns comportamentos que envolvem as características associadas aos itens aqui denominados de ações, e vice-versa. Isso acontece, por exemplo, quando dizemos que uma pessoa reagiu bem à determinada notícia. Meu uso das expressões 'ação' e 'reação', neste trabalho, procura apenas salientar que a gama de itens comumente considerados como comportamentos envolve desde itens relativamente automatizados e rígidos até aqueles mais espontâneos e flexíveis, bem como permitirme apontar comportamentos de um ou de outro lado desse espectro.
} 
força de objetos ou eventos do ambiente externo imediato, como, por exemplo, ter um braço ou uma pata erguido por outrem, receber um empurrão, ser arrastado por uma correnteza, os casos típicos de cair, tropeçar, resvalar, etc. (cf., e.g., Allen \& Bekoff 1997, p. 42; Dretske 1988, p. 1-2). Digo 'os casos típicos' porque, evidentemente, há casos em que um organismo produz sombras, cai, etc. de modo deliberado e, por conseguinte, com um propósito, ao invés de como produção de um resultado incidental ou por inteira força do ambiente externo imediato (o que, é claro, não significa que qualquer propósito envolva deliberação) $)^{3}$. Isso ocorre, por exemplo, quando uma pessoa projeta com a mão sombra sobre o próprio rosto para proteger-se da incidência solar ou tropeça, em uma peça de teatro, para representar um personagem.

Poder-se-ia pensar que as reações - incluindo ocorrências de padrões inatos de comportamento (como pelo menos vários reflexos incondicionados e, apesar da terminologia, os padrões modais de ação) e de padrões afins (como pelo menos vários reflexos condicionados $)^{4}$ - são, pelo seu relativo automatismo e rigidez, coisas efetuadas pela simples força do ambiente externo imediato; e, desse modo, coisas que não são realmente realizadas pelo organismo. Porém, esse não é o caso ${ }^{5}$. Pois essas ocorrências devem sua existência, em parte, a interações passadas com

\footnotetext{
Quando eu falar de propósito, aqui, salvo qualificação em contrário, estarei falando simplesmente da propriedade de ser dirigido a objetivos ou de ter uma ou mais funções. Ocorrências de reflexos e de padrões fixos (ou modais) de ação, por exemplo, possuem esse carácter. Não estou, de modo nenhum, assumindo que ações (que podem ser entendidas como ocorrências de padrões operantes) derivem de modo geral seu caráter propositivo ou funcional a partir deliberação. Antes, manterei, em grande parte deste trabalho, relativa neutralidade sobre a melhor maneira de modelar a noção de propósito ou função. Apenas as minhas propostas na parte final deste trabalho (especificamente, final da seção 4) envolvem uma compreensão mais específica dela.

4 A qualificação de que pelo menos vários reflexos incondicionados ou condicionados contam como reações visa preservar a intuição de que, prima facie, não é totalmente claro se alguns casos desses reflexos, como, por exemplo, os condicionados relacionados a secreções endócrinas, contam ou não como comportamentos no sentido de (i). Entretanto, no contexto de uma definição teórica de comportamento, pode-se distinguir critérios que tornem mais claras as fronteiras da noção e que, assim, permitam determinar se casos como esses a satisfazem ou não. A noção de definição teórica, como a entenderei no trabalho, é brevemente caracterizada na seção 2 .

5 Uma observação em certa medida semelhante a esta é feita por Dretske (1988, p. 3-5). Minha observação é neutra com respeito à sua concepção particular das ações.
}

o ambiente - podendo ser no âmbito filogenético ou no ontogenético (ou seja, respectivamente, da história da espécie do qual o organismo é membro ou de sua história individual), possivelmente em ambos os âmbitos. Se, por exemplo, como ocorrência de um reflexo (no caso, condicionado), um coelho contrair a pata dianteira direita frente a apresentação de um som, o fenômeno acontece sob condição de que certos fenômenos passados tiveram lugar resultando em o coelho ser sensível ao respectivo estímulo. Um coelho sem ter passado por uma história de pareamento do som (estímulo eliciador condicionado) com um estímulo eliciador incondicionado relevante não tenderia, tudo o mais sendo igual, a contrair a referida pata dada a presença daquele som. Além disso, o fato de que a mera movimentação da pata dianteira direita do coelho por inteira força de algo externo (e.g., a força do braço de alguém) não contaria como aquele comportamento também revela que se trata de um caso da acepção (i) da noção.

(ii) Comportamento enquanto padrão ou classe. Comportamento, na acepção (i), é uma ocorrência, isto é, um exemplar (instance) de um padrão (pattern) ou classe, ou uma entidade que, junto com entidades que possuem uma ou mais propriedades relevantes em comum, forma um padrão ou classe ao longo do tempo. O comportamento qua ocorrência é um processo, que tipicamente acontece em um momento e lugar específicos; por exemplo, erguer o braço para fazer uma pergunta a um palestrante, entre 17h30min10s e 17h30min16s do dia 14 de fevereiro de 2013, em tal e tal auditório de certa instituição. Já o comportamento qua padrão ou classe (e.g., um padrão operante, um reflexo) é algo realizável em momentos e lugares distintos, ou pelo menos é formado por coisas que ocorrem em momentos e lugares distintos, mas sem ele mesmo ter tal momentaneidade e localizabilidade (cf., e.g., Lee 1983). Por exemplo, erguer o braço para fazer uma pergunta, qua padrão ou classe de comportamento, é o tipo de coisa do qual faz sentido dizer poder, a princípio, existir desde a infância de uma pessoa e perdurar por toda sua vida, ser realizado hoje, amanhã, etc., e em múltiplos locais (e.g., diferentes salas de aula e auditórios). Logo, referência a um comportamento na acepção (i) implica, em geral, em referência implícita a um padrão ou classe que ele exemplifica ou forma, mas se trata de coisas diferentes. 
(iii) Comportamento de grupo. Não só organismos singulares exibem comportamentos, mas também grupos de organismos; por exemplo, o comportamento de vigiar uma colmeia ou de fabricar favos por um grupo de abelhas, o de caça por um grupo de leões, etc. Comportamentos de grupo, de modo análogo aos comportamentos dos organismos singulares, admitem ser entendidos como ocorrências ou como padrões. Quando são ocorrências, envolvem características similares àquelas associadas à acepção (i) da noção. Trata-se de coisas realizadas e que se dão em momentos e locais particulares. Correlatamente, não faz sentido dizer, por exemplo, que coisas que correspondem à produção de resultados incidentais por um grupo de organismos (e.g., a produção de sombras e sons no solo pelos leões ao estarem em grupo caçando gnus) contem como comportamentos do grupo (salvo, como veremos a seguir, em uma acepção diferente da noção). No entanto, ocorrências de comportamentos de grupo têm características peculiares, as quais residem em serem realizadas por meio de comportamentos na acepção (i) de dois ou mais organismos coordenadamente, de tal modo que produzem como consequência um resultado comum, por contraste a ser um resultado de apenas algum dos membros (cf., e.g., Pacherie 2011, p. 174-175; Searle 2002/1990, p. 94-95).

(iv) Comportamento como mudança ou movimento de um objeto (com relação aos seus arredores). A noção de comportamento é empregada em tal acepção tipicamente quando atribuímos comportamentos a objetos ditos inanimados, tais como rochas, fluídos, partículas e projéteis. Por exemplo, o movimento (ou mudança de posição espacial) de uma rocha ao afundar em uma superfície aquática é comportamentos em tal sentido. Podemos dizer, dentre outras coisas, que a rocha está se comportando a uma determinada velocidade média.

É coerente atribuir comportamento em tal sentido a organismos também, mas, em tais casos, a atribuição é diferente daquela de comportamento na acepção (i). Pois as atribuições de comportamento na acepção (i) excluem que conte como tal algo correspondente à mera produção de um resultado incidental pelo organismo e algo que faça por causa inteiramente de forças do ambiente externo imediato. Distinguimos, por exemplo, entre uma pessoa erguer seu braço para fazer uma pergunta e o braço mover-se por outrem erguê-lo; etc. Além disso, se uma pessoa ergueu a mão para fazer uma pergunta a um palestrante e aconteceu de o movimento do braço projetar uma sombra em algo (e.g., sobre uma formiga que acontecia de estar passando por perto), esse projetar a sombra, sendo meramente incidental (e não, e.g., algo feito pela pessoa para proteger-se da incidência solar), não é algo realizado pela pessoa, portando contando como comportamento apenas em outro sentido. Em outras palavras, comportamento na acepção (i) tem o que é por vezes chamado de um caráter teleológico, propositivo ou de ser dirigido a objetivos, ao passo que comportamento na acepção (iv) não (cf., e.g., Taylor 1964; Wright 1976). Portanto, comportamentos no sentido de (i) são fenômenos que dependem não só de mudança ou movimento de um organismo, mas também a outras propriedades. Logo, mudança ou movimento de um organismo não constitui uma condição suficiente de comportamento no sentido de (i), ainda que constitua uma condição necessária dele e, nessa medida, (i) possa ser considerado uma subcategoria de (iv) (cf. Rosenblueth et al. 1942).

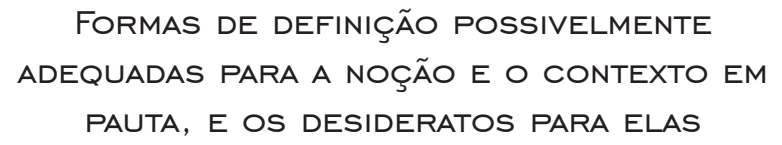

Nesta seção, procuro, primeiro, delimitar as formas de definição possivelmente adequadas para a noção de comportamento na acepção (i) - doravante, referida apenas pelo termo 'comportamento' ou sua forma plural, salvo qualificação em contrário - e para o contexto aqui relevante; e, segundo, delimitar os principais desideratos para elas.

Apenas alguns tipos de definição são possivelmente adequados para a noção e o contexto em pauta. Pois (A) esse contexto é o de definições com o propósito de explicitar as condições que delimitam o que conta e o que não conta como comportamento (na acepção relevante). Algumas dessas definições podem dispensar comprometimento com a ideia que haja algo como a natureza dos comportamentos em geral; mas há em comum entre as definições nesse contexto o interesse pelo menos em explicitar as condições que determinam o que conta como comportamento e, desse modo, o que fica de fora da extensão do conceito. Além disso, (B) a noção em 
pauta não é nova, antes sendo uma noção ordinária, da qual já se possui um domínio tácito. Não é de interesse nele atribuir um significado inteiramente novo à noção, antes suas nuanças mínimas sendo pressupostas. E (C) a noção (conforme se segue da seção anterior) é tal que os itens de sua extensão possuem feições em comum. Estas devem figurar ou ser preservadas, de alguma maneira (mesmo que reduzidas a outras noções), no definiens, em termos de uma ou mais condições necessárias (salvo se houver justificação para uma grande mudança na maneira como o conceito funciona; mais sobre isso adiante).

Em (A), expressa-se que o tipo de definição de interesse aqui quanto ao propósito que uma definição pode ter é aquele por vezes chamado de teórico (cf., e.g., Copi 1982). Esse tipo de definição contrasta, por exemplo, com definições persuasivas, cujo propósito é muito diferente (a saber, provocar uma atitude de apreço ou desapreço com relação ao que é designado pelo definiendum). De (A) e (B) segue-se, por exemplo, que definições inteiramente lexicográficas (cujo propósito é aumentar o vocabulário de alguém - e.g., quando se ensina um vocábulo a um aprendiz de uma língua -, ou distinguir diferentes acepções do definiendum reduzindo sua ambiguidade - e.g., a entrada de um dicionário distinguir diferentes significados de um termo) não servem para o contexto aqui relevante (para detalhes, ver Lazzeri no prelo 1).

Tem-se de (A)-(C) que, quanto à técnica subjacente, os tipos de definição possivelmente adequados para a noção e o contexto em pauta são, em geral: definições por gênero e diferença específica (as quais envolvem a técnica de especificar condições individualmente necessárias e conjuntamente suficientes para o definiendum); definições operacionais (as quais têm como técnica especificar operações - no sentido de procedimentos de teste ou de mensuração - que, uma vez efetuadas, estabelecem se algo satisfaz ou não o definiendum); e definições disjuntivas (as quais têm como técnica especificar disjunções - no sentido inclusivo de disjunção - de duas ou mais condições individualmente suficientes, mas não conjuntamente necessárias, para a predicação do definiendum), em particular as disjuntivas que admitem que o definiens inclua uma ou mais condições necessárias relevantes, ainda que implicitamente (a saber, como elementos comuns aos diferentes disjuntos) (para detalhes, ver Lazzeri no prelo 1). Ficam excluídas definições de tipo extensionais (cuja técnica é explicitar a extensão do definiendum - e.g., definir comportamento por enumeração de exemplos de comportamento) e sinônimas (cuja técnica é estabelecer uma palavra sinônima àquela que nomeia o definiendum - e.g., definir comportamento como conduta). Também o ficam o subtipo de definições disjuntivas que Cooper (1972) chama de definições de suficiência (as quais não admitem sequer implicitamente que o definiens inclua uma ou mais condições necessárias relevantes no definiens - como ocorre, e.g., em uma caracterização adequada da noção de jogo segundo celebremente sugeriu Wittgenstein 1953, §§65ss), o que se segue em particular de (C). Em outras palavras, tem-se de (C) que o conceito de comportamento na acepção aqui relevante $n a ̃ o$ é um conceito de agregados (cluster concept) ou de semelhanças de família (em uma caracterização usual de conceitos de agregados ou de semelhanças de família, isto é, como conceitos que não admitem como definiens nenhuma condição relevante necessária). Por fim, deixo em aberto se as definições recursivas (cuja técnica consiste nos três respectivos passos: identificação de membros iniciais do conjunto sendo definido; especificação de uma condição de acordo com a qual determinados itens são membros do conjunto se possuem certas relações com os membros inicialmente especificados; e declaração de que nada mais conta como membro dele) são apropriadas para o conceito na acepção relevante. Aparentemente não se trata de um conceito para o qual possa haver uma condição correspondente ao segundo passo desse tipo de definição; mas, em todo caso, os desideratos que sugiro a seguir aplicamse também a ele.

Estou agora em posição de listar desideratos para uma definição de comportamento (na acepção i), uma vez que os desideratos para uma definição não são absolutos, antes sendo relativos aos tipos de definição que se tenha em vista. Logo, os desideratos a seguir são relativos pelo menos aos tipos de definição delimitados anteriormente (a saber, definições teóricas, sob a forma de definições por gênero e diferença específica, definições disjuntivas que admitam alguma condição necessária e definições operacionais; quiçá também as recursivas). Ei-los: 
(a) Não ser demasiado abrangente: o definiens não deve denotar mais coisas do que é denotado pelo definiendum;

(b) Não ser demasiado restritiva: o definiens não deve denotar menos coisas do que é denotado pelo definiendum;

(c) Não ser viciosamente circular: o definiendum não deve figurar no definiens, sequer implicitamente (excetuando-se uma circularidade não viciosa $\left.{ }^{6}\right)$;

(d) Ser informativa: o definiens deve contribuir para aclarar nosso entendimento intuitivo do definiendum;

(e) Capturar, em geral, as nuanças mínimas do conceito: o definiens deve preservar as regras associadas ao uso típico do conceito (excetuando-se revisão conceitual justificada).

Segundo o desiderato (a), é falha uma definição de comportamento segundo a qual, por exemplo, ele equivale a movimentos do corpo; pois acaba incluindo na extensão do definiendum itens que contam como comportamento apenas na acepção (iv) da noção (como o frequente movimento de um organismo em torno do eixo terrestre). Segundo (b), é falha uma definição de comportamento de acordo com a qual, por exemplo, ele é apenas algo feito deliberadamente, porquanto exclui da extensão do definiendum comportamentos relativamente automatizados (como as ocorrências de padrões inatos de comportamento). Conforme (c), mostra-se implausível uma definição de comportamento em termos, digamos, de ação causada por evento do ambiente, se o termo 'ação' estiver sendo usado por referência a uma subclasse de (i) (a saber, a de ocorrências de ações), ou como um sinônimo de comportamento no sentido de (i); porque, nesse caso, tenta-se elucidar o definiendum em termos que já o pressupõem, de modo vicioso. Por sua vez, o critério (d) visa evitar que a definição não cumpra o papel de uma definição teórica. Afirmar, por exemplo, que comportamento consiste em atividade do organismo não aumenta nosso entendimento intuitivo sobre as condições que estabelecem a extensão do conceito.

Uma pergunta que pode surgir naturalmente

\footnotetext{
Segundo alguns autores (e.g., Burgess 2008), a circularidade não é viciosa (mas, antes, virtuosa) quando acaba sendo informativa.
}

acerca desses desideratos, sobretudo de (a) e (b), é: qual pedra de toque, ou parâmetro, que temos para aplicá-los? Considero que um parâmetro principal que temos para tanto é capturada pelo desiderato (e). Ou seja, sugiro que as nuanças mínimas associadas à noção em pauta, as quais podem ser trazidas à tona por meio de análise conceitual, constituem um parâmetro geral para aplicação dos outros desideratos sugeridos, em particular (a) e (b). Ao dizermos, por exemplo, que é demasiado abrangente uma definição de comportamento que conte como tal coisas como um organismo sendo empurrado ou girando em torno do eixo terrestre, estamos detectando uma incoerência com nuanças mínimas da noção; nomeadamente, uma incoerência com seu caráter teleológico. Ao dizermos que é demasiado restritiva uma definição de comportamento que não conte como tal ocorrências de reflexos, estamos apontando para o fato de que, na verdade, as nuanças mínimas da noção são satisfeitas por esses itens. $\mathrm{Na}$ formulação de uma definição teórica de comportamento, podemos quiçá seja até preciso - ir além do que a análise das regras subjacentes ao uso típico da noção por si só revela; mas é desejável que, ao fazê-lo, mantenhamos coerência com essas regras, sob pena de incorrer em arbitrariedade no definiens e perder de foco o definiendum.

Isso não significa, entretanto, que nuanças associadas à noção não possam legitimamente ser questionadas. Com a qualificação 'em geral', em (e), viso salientar que essa possibilidade não está excluída. No entanto, nem toda revisão conceitual é justificável, sob pena de perder de vista a noção. Por exemplo, se quisermos dizer que o comum girar em torno do eixo terrestre é comportamento, estaremos rejeitando as particularidades da acepção (i) e equiparando-a à acepção (iv). Por isso, penso que, muitas vezes, quando um autor faz uma revisão conceitual, não o faz por realmente querer modificar a noção (no caso anterior, por exemplo, o autor provavelmente não o faria por desejar nivelar os comportamentos dos organismos a comportamentos no sentido de iv), mas, antes, por negligenciar suas nuanças ${ }^{7}$.

\footnotetext{
A meu ver, portanto, não é satisfatória a ideia de que a noção em pauta, quando presente no âmbito de uma teoria científica, deva ter seu significado adquirido simplesmente em razão dos comprometimentos da teoria (se esta realmente tiver em vista a noção). Ela poderá fazer revisão conceitual, mas essa revisão terá que ter justificação.
} 
Por fim, saliento que a lista de desideratos aqui sugerida não pretende ser exaustiva. Podese considerar como um desiderato que a definição seja econômica, de modo a não emperrar o uso do conceito (e.g., Levitis et al. 2009, p. 104). Porém, uma definição que não é tida como econômica em um momento pode tornar-se econômica, em razão do que optei por prescindir desse critério neste trabalho. Em todo caso, sugiro que um tal desiderato deve andar em harmonia com aqueles aqui apontados.

\section{AlgumAS DEFINIÇÕES DE COMPORTAMENTO ENCONTRADAS NA LITERATURA CIENTIIFICA E FILOSÓFICA: UMA REVISÃO CRÍTICA}

Com base nas distinções estabelecidas nas seções anteriores, procedo a um exame de várias definições de comportamento (na acepção i) encontradas na literatura científica e filosófica (algumas delas apenas afirmadas ou assumidas) ${ }^{8}$.

(I) Comportamento como mudança ou movimento do corpo, ou (se for uma ação) mudança ou movimento do corpo causado por estados mentais apropriados. Alguns autores supõem que os comportamentos, ou pelo menos aqueles que não correspondem a ações, equivalem a simples movimentos ou mudanças do corpo. Goldberg e Pessin (1997, p. 128-129), por exemplo, sugerem, ao caracterizarem as ações, que os comportamentos que não são ações equivalem a isso. As ações, segundo Goldberg e Pessin (1997), são movimentos e "ruídos" do corpo causados por fenômenos mentais apropriados (em especial, crenças e desejos), diferindo de comportamentos que não são ações apenas em terem essas supostas causas:

É instrutivo considerar a distinção que frequentemente fazemos entre movimentos e ruídos corporais que são ações daqueles que são 'meros' movimentos e ruídos corporais. ... Para começar, os movimentos e ruídos corporais em questão (roncos no estômago, reflexos, movimento forçado externamente) não são movimentos iniciados pela própria pessoa. ... [É] manifesto que esses movimentos e ruídos corporais não contam como ações ..., pela simples razão de que nenhum deles têm uma causa mental. ... A distinção entre ações

As ponderações feitas nesta seção não têm necessariamente por implicação um questionamento de outros aspectos dos trabalhos em que essas definições se encontram. e meros movimentos corporais, portanto, parece ser uma distinção entre comportamentos que têm uma causa mental e comportamentos que não a têm. (Goldberg \& Pessin 1997, p. 129; grifos dos autores)

Mele e Moser (1994), de modo semelhante, declaram: "Remova o intencional inteiramente da ação intencional e você tem mero comportamento: bruto deslocamento corporal não dissimilar ao movimento da areia varrida pelo vento nas margens do Lago Michigan" (p. 39). Depreende-se do texto de Mele e Moser que, nesse caso, estão empregando o termo 'ação' sem a qualificação 'intencional' como sinônimo de 'comportamento' e, por sua vez, o termo 'intencional' com a conotação de alguma forma de causação mental não envolvida em ocorrências de reflexos e padrões similares. Tal caracterização sugere haver em comum entre os comportamentos que são ações e os demais apenas as feições de comportamento na acepção (iv).

Conforme apontam Block e Hornsby, as versões tradicionais de (o que não significa qualquer) funcionalismo em filosofia da mente assumem uma definição de comportamento nesses termos. Hornsby (2006/1986) afirma: "Quando os funcionalistas falam em comportamento, falam ... em movimentos corporais, ou então falam em respostas motoras" ( $p$. 34). Nas palavras de Block (1978): “Os funcionalistas tendem a especificar ... saídas [outputs] em termos de movimentos de braços e pernas, som emitido e coisas do tipo" (p. 316). Lewis (1974) é explícito a esse respeito ao dizer que emprega o conceito para se referir a "movimentos corporais e afins" (p. 338). É possível, porém, que as referidas abordagens assumam, implicitamente, uma distinção similar àquela de Goldberg e Pessin (1997) e de Moser e Mele (1994). Entretanto, não quero entrar em uma questão exegética aqui. $\mathrm{O}$ importante é que, em qualquer caso, essas caracterizações implicam na seguinte definição (disjuntiva): algo é comportamento se, e apenas se, é uma mudança ou um movimento do corpo, ou (caso for uma ação) uma mudança ou um movimento do corpo causado por estados mentais apropriados. Tal de definição acaba sendo, no mínimo, demasiado abrangente, isto é, transgride o desiderato (a), como indico a seguir. 
É correto contrastar ações ("ações intencionais", na terminologia de Mele e Moser) com comportamentos tomados acepção (iv), já que estes, diferentemente daquelas, não possuem feições teleológicas (conforme salientei na seção 1). Pode-se dizer isso independentemente de entrar no mérito de se tais autores oferecem ou não uma caracterização apropriada das ações. Contudo, ao equipararem todo comportamento que não é ação com comportamento na acepção (iv), eles incorrem em um grande equívoco, uma vez que (consoante apontei na seção 1) há comportamentos que não são ações e que, no entanto, são itens da extensão do conceito na acepção (i); a saber, comportamentos relativamente mais automatizados e rígidos, como, por exemplo, as ocorrências de padrões inatos de comportamento. Tais fenômenos possuem características em comum com as ações e que os tornam, não menos do que estas, incompatíveis com uma redução a movimentos ou mudanças do corpo tomados por si.

(II) A definição de Tinbergen. Tinbergen (1951) define comportamento como "o total de movimentos feitos pelo animal intacto" (p. 2). Na medida em que se cinge a movimentos do animal intacto, trata-se de uma definição em termos puramente topográficos (isto é, relativos a propriedades físicas do corpo do organismo).

Essa definição revela-se insatisfatória sob alguns aspectos. O primeiro deles (o qual, entretanto, é menor, porque pode ser retificado sem dificuldade) é falhar quanto ao desiderato (b), isto é, ser muito restritiva, posto que limita o âmbito do conceito apenas aos animais, quando, na verdade, plantas também realizam comportamentos. Alguns dos comportamentos de plantas conhecidos popularmente são aqueles do girassol inclinando-se em direção à luminosidade do sol, da planta sensitiva (Mimosa pudica) fechando as folhas de seus ramos ao serem tocados e da planta carnívora capturando um inseto. Alguém poderia pensar que, por serem automatizados e rígidos, esses comportamentos não diferem daqueles tomados na acepção (iv). Porém, esse não é o caso. Se o fosse, então, por exemplo, se um girassol, por simples força de uma ventania ou de uma pessoa que o contorcesse pelo caule, exibisse os mesmos movimentos que costuma exibir quando se volta para o sol, tais movimentos contariam como seu comportamento, o que não ocorre. Além disso, note- se que a individuação do comportamento da planta se dá pela referência a um propósito ou função (sem, evidentemente, envolver deliberação) - no caso, relacionado à obtenção da luz do sol -, portanto não sendo apenas movimentos. Contudo, a definição de Tinbergen pode abranger comportamentos de plantas bastando substituir 'animais' por 'organismos' em seu definiens.

No entanto, essa definição falha quanto a (b) também pelo fato de que movimentos não constituem sequer uma condição necessária para a individuação de todos os comportamentos (ainda que, sim, de vários deles), havendo comportamentos que não envolvem movimentos. Por exemplo, isso parece ser o caso nos comportamentos de certas cobras fingirem-se de mortas ficando imóveis, de um animal esconder-se de um predador em uma árvore, de uma pessoa ficar sentada aguardando algo, de fingir estar dormindo, dentre outros (cf., e.g., Allen \& Bekoff 1997, p. 41-42; Dretske 1988, p. 1-2, p. 28-29). O organismo pode mover-se enquanto realiza um desses comportamentos, mas seus movimentos não constituem condição necessária deles.

Pode-se tentar contornar esse último problema qualificando que o total de movimentos feitos pelo animal intacto admite ser nulo. Entretanto, essa definição, em todo caso, mostra-se incapaz de capturar nuanças mínimas da noção. Em particular, ela não captura o caráter teleológico dos comportamentos, revelando-se falha quanto ao desiderato (a), ou seja, demasiado abrangente. Um animal intacto pode executar um total de movimentos que não corresponde a um comportamento, como pode acontecer, por exemplo, se resvalar, cair, sofrer um empurrão, ser arrastado por uma correnteza, etc. Note-se que essa definição acaba incluindo na extensão do definiendum até mesmo o comum giro em torno do eixo da Terra feito pelo organismo intacto. Assim, a definição mostra-se implausível.

(III) A definição de Watson (1919). Watson (1919) define comportamento como "o total de mudanças de músculos estriados e não estriados e de glândulas que se segue a um dado estímulo" (p. 14). Como menciona Watson (1919, p. 13), os músculos estriados estão envolvidos na movimentação de braços, pernas, língua, tronco e laringe, ao passo que os não estriados no controle de vasos sanguíneos, intestinos, órgãos de eliminação e órgãos reprodutivos. 
Por estímulo, ele entende uma mudança do ambiente que causa o comportamento, seja uma mudança no ambiente externo ao corpo ou uma correspondente aos movimentos musculares e secreções no interior do corpo (Watson 1919, p. 9-10). Comportamentos e estímulos complexos (e.g., o comportamento de dirigir um carro), para Watson, reduzem-se a conjuntos de (respectivamente) comportamentos e estímulos entendidos nesses termos (Watson 1919, p. 10-14).

A meu ver, essa definição mostra-se igualmente implausível. Uma primeira limitação dela é falhar quanto ao desiderato (b), posto que se cinge a animais. Esse problema, porém, como no caso de (II), pode ser evitado pela introdução em seu definiens de uma ou mais disjunções que acomodem os movimentos de estruturas similarmente relevantes de outros seres vivos.

No entanto, uma segunda limitação dela é mais central; a saber, quanto ao desiderato (a), porque um total de mudanças de músculos e glândulas que se segue a um dado estímulo pode corresponder a coisas que não são comportamentos. Por exemplo, pode corresponder ao total de mudanças de músculos e glândulas ocorrido ao um organismo cair (o que inclui, e.g., os músculos e glândulas moverem-se até a altura do solo), considerando-se que o respectivo total de mudanças envolvido é causado por certos acontecimentos antecedentes do ambiente (e.g., a presença de um buraco no caminho). É incoerente com as nuanças do conceito dizer que esse total de mudanças de músculos e glândulas - qua total de mudanças da queda - corresponde a um comportamento (salvo, é claro, em outro sentido do conceito, que não é aquele do definiendum). Se o organismo, quando estiver caindo, mover membros do corpo de modo a acomodar a queda, então parte de seu total de movimentos de glândulas e músculos pode contar como comportamento; mas qua total de mudanças da queda não contam como comportamento. Mesmo que se considere que possa contar como tal, note-se que o organismo pode cair sem se proteger ou fazer algo similar. Em outras palavras, a definição de Watson (1919) não é capaz de preservar as nuanças teleológicas da noção, acabando por incluir em sua extensão acontecimentos que não possuem nenhum caráter propositivo ou funcional ${ }^{9}$.

\footnotetext{
Tolman (1932, p. 4ss) pioneiramente ponderara isso a respeito dessa definição, mas, a meu ver, de modo não inteiramente
}

(IV) Comportamento como qualquer coisa que um organismo faça. Muitos autores (incluindo Bunge \& Ardila 1987, p. 222; Chance 2003, p. 37, p. 448; Davis 1966, p. 2, p. 4-5; Lehner 1996, p. 8; Myers 2010, p. 6; Peirce \& Cheney 2004, p. 1; Solomon et al. 2008, p. 1101; Watson 1930 , p. 6-7) ${ }^{10}$ definem comportamento em termos de "qualquer coisa que um organismo faça" ou "aquilo que o organismo faz". Há variantes dessa definição. Na formulação de Chance (2003), Peirce e Cheney (2004) e Watson (1930), supõe-se que se trata de algo que possa ser mensurado, ainda que não necessariamente observável no exterior do corpo. Tais autores desejam contar como itens da extensão do definiendum fenômenos psicológicos ou mentais entendidos por eles como sendo inobserváveis exteriormente mas suscetíveis à mensuração, como os de raciocinar, os humores e assim por diante. Já Myers especifica a condição complementar de que se trata de algo que possamos observar e registrar, pretendendo explicitamente com isso excluir da extensão da noção fenômenos psicológicos. Ele diz: "Processos mentais são as experiências internas, subjetivas, que inferimos a partir do comportamento" (Myers 2010, p. 6; meu grifo).

Essa definição possui dificuldades conceituais. Uma primeira ponderação que ela requer, em particular a versão dela em que se pretende considerar fenômenos psicológicos como comportamentos, é de que alguns fenômenos psicológicos têm caráter de estados. Esse é o caso, por exemplo, dos humores e apetites. Estados, diferentemente de comportamentos, não são coisas que um organismo realiza. Sequer faz sentido dizer que um estado seja algo que um organismo faça (antes sendo algo em que um organismo está). Não quero dizer com isso que esses fenômenos não sejam constituídos por comportamentos. Na verdade, eu penso (por razões que estão para além do âmbito deste trabalho) que comportamentos são componentes centrais deles e de outros fenômenos psicológicos (Lazzeri no prelo

satisfatório. Isso porque Tolman considera que a definição de comportamento presente em Watson (1930) - a saber, em termos de qualquer coisa que um organismo faça - abrange seu caráter propositivo (Tolman 1932, p. 5-7), o que, como apontarei a seguir, na verdade não é o caso.

10 A definição dada por Skinner (1938, p. 6), que não é totalmente clara, talvez se qualifique como outro exemplo aqui. Porém, a maneira como Skinner pensa a noção é diferente; e é uma maneira que tem provavelmente uma de suas melhores expressões na formulação de Moore (2008), que examinarei mais adiante. 
2, no prelo 3). Porém, não se deve considerar um fenômeno psicológico que tenha caráter de estado como um comportamento simpliciter.

Dito isso, chamo atenção para o fato de que essa definição, em qualquer uma de suas variantes, transgride o desiderato (a), pois há coisas que um organismo faz que não contam como comportamento. Apesar de ela ter o mérito de excluir da extensão do definiendum coisas tais como uma mera queda de um cabelo e um arranhão (já que esse não é o tipo de coisa que um organismo faça), não exclui várias outras coisas que tampouco contam como itens da extensão dele. Como coloca Millikan:

$\mathrm{Na}$ verdade, muito poucas coisas que um organismo faz são comportamentos. 'Fazer' é uma noção bem mais geral do que a de 'comportar-se'. Para 'fazer' [algo], precisa-se meramente satisfazer um verbo ativo. Verbos ativos, em sua maioria, são sem compromisso quanto a se aquilo que descrevem é ou não a realização de uma função ou propósito. (Millikan 1993a, p. 144; grifos da autora)

Ou seja, frequentemente, basta haver a aplicação efetiva de um verbo ativo para termos a designação de algo que um organismo faz. Porém, tais verbos, em muitos casos, não designam comportamentos. Por exemplo, um organismo, ao forragear, pode projetar sombra no chão, despertar atenção de um predador, tropeçar em um galho, etc., o que são coisas que ele faz; mas, como o faz incidentalmente, não se trata de comportamentos. Em outras palavras, esses acontecimentos, diferentemente dos comportamentos, não possuem nenhum propósito ou função.

Além disso, de modo correlato, algo que um organismo constantemente faz é movimentar-se; mas (conforme argumentei na seção 1), movimentos de um organismo, considerados por si mesmos, estão longe de constituir uma condição suficiente para haver comportamento. Em suma, tem-se que, embora o comportamento seja em parte algo que o organismo faz, dizer que ele consiste nisso simplesmente sem mais implica em falha quanto ao desiderato (a).

(V) Comportamento como atividade do organismo, ou como atividade em que se engaje. Vários autores (incluindo Donahoe \& Palmer 1994, p. 3; Powell et al. 2009, p. 3, p. 501; S. T. Watson \& Brown 2011, p. 221) definem comportamento em termos de qualquer atividade do organismo. No caso da formulação de Donahoe e Palmer (1994, p. 3) e de S. T. Watson e Brown (2011, p. 221), comportamento é definido, mais especificamente, como qualquer atividade na qual um organismo se engaje. Tanto nessa formulação como naquela de Powell et al. (2009, p. 3, p. 501), as atividades são concebidas como podendo ser internas (e.g., secreção de saliva por um cão). Consideram como atividades internas do organismo inclusive pelo menos alguns fenômenos psicológicos (mas não fica claro qual é o âmbito deles que os autores pretendem abranger).

À primeira vista, tal definição pode aparentar praticamente não diferir da definição (V). No entanto, trata-se, na verdade, de definições com diferenças, porque nem tudo que um organismo faz é uma atividade. Por exemplo, um organismo refletir luz ao ser exposto ao sol, tropeçar em um galho e atrair atenção de um predador são coisas que ele faz, mas não são, nos casos típicos, atividades. A definição de comportamento em termos de atividade tem a vantagem sobre $(\mathrm{V})$ de excluir da extensão do definiendum esses acontecimentos.

Entretanto, penso que essa definição tampouco se releva suficientemente plausível - pelo menos como definição teórica. Uma primeira ponderação que ela requer, em particular sua variante que pretende incluir fenômenos psicológicos como comportamentos, é de que (conforme apontei anteriormente) alguns fenômenos psicológicos têm caráter de estados, o que contrasta com atividades do organismo. Não é claro qual exatamente é o leque de categorias de fenômenos psicológicos os autores pretendem abranger nessa definição, mas convém ter em conta esse pormenor, sob pena de transgredir nuanças mínimas do definiendum.

Esse possível problema não é crucial, uma vez que pode ser contornado sem dificuldade (bastando não fazer menção no definiens à possibilidade de inclusão de fenômenos psicológicos com caráter de estado). Porém, pelo menos a variante dessa definição sem a condição de que as atividades sejam aquelas nas quais um organismo se engaje revelase insatisfatória por outra razão, em particular quanto ao desiderato (a). A razão é de que acaba incluindo atividades desenvolvimentais na extensão do definiendum, tais como aquelas de formação ou crescimento de sistemas e órgãos do corpo (e.g., sistema digestivo, coração, ossos, dentes) e de partes 
afins da anatomia do organismo (e.g., braços, pernas, patas, bicos, penas, cabelos, pelos, unhas, escamas, carapaças). Pelo menos muitas dessas atividades não são o tipo de coisa que conta comportamento, antes estando relacionadas apenas a precondições de comportamentos, na medida em que eles dependem de substratos resultantes de tais atividades.

Tal como os comportamentos, as atividades desenvolvimentais possuem funções e, além disso, possuem um caráter episódico - ainda que geralmente sejam muito mais estendidos no tempo -, o que faz com que seja pouco claro em que elas exatamente diferem dos comportamentos. Acredito que um critério que delimita a fronteira entre atividades desenvolvimentais - pelo menos aquelas que claramente não chamamos de comportamentos - e atividades comportamentais é o de que estas últimas envolvem influência direta de estímulos sensoriais, sejam exteroceptivos, proprioceptivos ou interoceptivos (isto é, relacionados respectivamente aos sistemas sensoriais exteroceptivos, proprioceptivos ou interoceptivos), enquanto que pelo menos muitas daquelas outras (presumivelmente) não.

Pode-se alegar que a variante dessa definição em que comportamento é caracterizado como atividade na qual um organismo se engaje escapa a esses contraexemplos. Em qualquer caso, sugiro que tanto esta como a outra variante da definição não servem como definições teóricas, embora eventualmente possam servir como definições lexicográficas - e é bem possível que seus autores tenham-nas formuladas não mais do que como tais. A alguém que procure saber as condições que delimitam a extensão do conceito, há pouco acréscimo de entendimento em dizer que comportamento é qualquer atividade do organismo ou qualquer atividade em que se engaje. Isso é semelhante a, diante de alguém que esteja interessado em saber, digamos, em que consiste o processo de ouvir algo, dizer que se trata de qualquer processo pelo qual um organismo percebe os sons aos seus arredores; ou seja, é algo pouco informativo. Em outras palavras, trata-se de uma definição que não satisfaz ao desiderato (d).

(VI) A definição de Marken. Segundo Marken (1982), "Comportamento pode ser objetivamente definido como resultados controlados das ações de um organismo" (p. 650). Por um resultado controlado, Marken entende "um resultado que é mantido em combinação com uma referência interna dentro do organismo para o estado daquele resultado. A referência interna corresponde a uma intenção e é a causa do resultado tencionado" (Marken 1982, p. 648). Ou seja, Marken sugere que comportamentos são os resultados causados por intenções, estas tomadas por ele como entidades internas ao organismo. $\mathrm{O}$ autor tem como motivação explícita para essa definição excluir que meros efeitos incidentais contem como comportamentos. A proposta consegue inclusive ficar imune de maneira mais geral às ponderações de demasiado abrangência a definições anteriormente examinadas. Pois eventos que ocorrem por simples força do ambiente externo imediato, bem como atividades desenvolvimentais, tampouco são o tipo de coisa que resultante das concebidas intenções internas.

No entanto, essa proposta é insatisfatória sob outros aspectos. Em primeiro lugar, é equivocado dizer que comportamentos sejam, em geral, resultados de ações. Resultados são produzidos por comportamento. Além disso, muitas vezes o são sem eles mesmos serem comportamentos. Quando, por exemplo, uma pessoa escova bem os dentes, tem como resultado os dentes ficarem limpos, mas os dentes ficarem limpos não é algo que corresponda a um comportamento. Em segundo lugar, essa definição pode ser acusada de falhar quanto a (b), pela razão de que nem tudo que é comportamento envolve intenção no sentido de deliberação ou vontade - conotação que o autor parece adotar -, como é o caso das ocorrências de padrões inatos de comportamento ${ }^{11}$.

(VII) Comportamento como relação entre organismo e ambiente. Alguns autores (e.g., Jessor 1958, p. 172-173; Maturana 1995, p. 151-152) consideram que o comportamento consiste em uma relação do organismo vivo inteiro e o ambiente. Nos termos de Maturana (1995), comportamento é "uma relação entre um sistema vivo operando como um todo e o meio operando como uma entidade independente" (p. 151). Nessa definição, comportamento não é entendido como o elemento de uma relação do organismo com o ambiente, mas como sendo ele próprio a relação.

1 Saliento ainda que Marken adota pressupostos muito problemáticos sobre a noção de intenção em seu definiens, mas não discorrerei sobre isso neste trabalho; a respeito desse assunto, cf., e.g., Lazzeri 2013b, no prelo 3. 
Essa definição é bem motivada, pretendendo evitar confusões entre os sentidos (i) e (iv) do conceito, mas não é imune a dificuldades conceituais. Em particular, ela é incoerente com a nuança do conceito segundo a qual comportamento é algo emitido ou realizado pelo organismo. Como aponta Todorov (2012), não faz sentido dizer que um organismo emite ou realiza uma relação entre ele e o ambiente. É correto dizer que o comportamento é um elemento de uma relação com o ambiente, já que, não se reduzindo a mudanças ou movimentos do corpo, ele é individuado por referência a propriedades para além das dimensões topográficas que possua. Porém, isso não significa que ele seja a própria relação entre o organismo vivo inteiro e o ambiente. Há uma diferença entre comportamento ser uma relação organismo-ambiente e comportamento ser algo que possui propriedades relacionais envolvendo elementos do ambiente como relata.

(VIII)Adefiniçãode Bergner.Uma das propostas mais recentes de definição de comportamento (até o momento) foi feita por Bergner. Sua definição é a seguinte:

Qualquer comportamento ... é um estado de coisas complexo que inclui como estados de coisas que o compõem uma pessoa específica agindo para realizar os propósitos $\mathrm{W} 1 \ldots \mathrm{Wn}$, agindo sob as discriminações $\mathrm{K} 1 \ldots \mathrm{Kn}$, exercitando competências [competences] K-H1...K-Hn, engajando-se em processos físicos ou realizações [performances] P1...Pn, alcançando resultados A1...An, expressando características pessoais $\mathrm{PC1}$...PCn e engajando-se em ações tendo os significados S1...Sn. (Bergner 2011, p. 148-149)

Bergner (ao falar em termos de 'uma pessoa agindo', etc.) utiliza a noção de ação no definiens, de modo que, salvo se a utiliza significando algo que não implique o conceito de comportamento, incorre em problema quanto ao desiderato (c); ou seja, em circularidade viciosa. Como convém adotar o princípio de caridade na interpretação, assumo que o autor não esteja utilizando o conceito de ação de modo equivalente ao de comportamento (na acepção i) ou de modo dependente dele. Podemos entender a presença dele em tal definiens em termos, por exemplo, de fazer algo.
Cabe apontar que, ainda assim, a proposta de Bergner é implausível, posto que transgride (b), dado que se limita aos comportamentos de pessoas, deixando de lado a rica gama de comportamentos que encontramos nos seres vivos em geral. Esse problema, no entanto, pode ser retificado substituindo-se no definiens 'pessoas' por 'organismos'.

Porém, a proposta transgride (b) de modo mais grave. Pois não inclui comportamentos relativamente automatizados e rígidos na extensão do definiendum (e.g., as ocorrências de padrões modais de ação). Em primeiro lugar, é dúbio dizer que qualquer comportamento seja exercício de uma competência. Pois a noção de competência conota tratar-se de algo de algum modo útil ao organismo, mas há reflexos, particularmente de tipo condicionado, que não são úteis (e.g., uma pessoa aumentar o batimento cardíaco cada vez que vê determinado tipo de objeto totalmente inofensivo, por algo muito desagradável ter acontecido alguma vez com ela ao mesmo tempo em que um objeto desse tipo estava presente). Em segundo lugar, as ocorrências de padrões inatos, pelo menos comumente, não expressam características pessoais. Que característica pessoal expressa, por exemplo, o comportamento de dança de uma abelha para indicar a direção e a distância de néctar? Bergner reconhece deixar de lado esses fenômenos, sob a assunção explicita que são meros movimentos, e não comportamentos no sentido relevante (Bergner 2011, p. 151). Isso, conforme previamente argumentei, é um grande equívoco.

(IX) A definição de Dretske. Drestke (1988, p. 1ss) define comportamento como o processo de uma causa no interior do organismo produzir um movimento corporal ou (de modo mais geral) uma mudança corporal (incluindo inibição de movimento do corpo). Segundo Dretske, a mudança corporal pode ter um efeito (possivelmente remoto) no ambiente externo, de modo que, nesse tipo de caso, comportamento, além de ser um processo de uma causa interna produzir essa mudança corporal, é também, por transitividade, o processo de certa causa interna produzir certo efeito no ambiente externo (Dretske 1988, p. 21-22). Além disso, a causa interna pode ser, antes, um conjunto de causas internas. Esquematicamente, tem-se que, comportamento, segundo essa perspectiva, é: o processo de um conjunto $C$ de estados ou eventos localizados no 
interior do corpo causar uma mudança corporal $M$ ou uma consequência externa, possivelmente remota, $N$. Note-se que, nessa proposta, comportamento não é algo causado por um ou mais estados ou eventos internos; mas, antes, um processo de um ou mais estados ou eventos internos causarem um movimento corporal ou consequência externa. Dretske enfatiza ser uma condição necessária para que algo seja comportamento que envolva uma causa com locus interno ao corpo, julgando que essa condição exclui que coisas que aconteçam ao organismo por inteira força externa sejam comportamentos. Ademais, essa definição acomoda a ideia de que alguns comportamentos não requerem movimento (e.g., um urso hibernar, alguém ficar sentado).

Para auxiliar sua definição, Dretske (1988, pp. 42-44) apresenta uma distinção entre causas disparadoras (triggering causes) e causas estruturadoras (structuring causes). Causas disparadoras são eventos $S$ do ambiente que causam $C$ (que, por sua vez, causa um movimento $M$ ou consequência $N$ ). Causas estruturadoras são eventos que determinaram um processo de $C$ causar $M$ ou $N$, isto é, eventos que causaram $C$ causar $M$ ou $N$ ao invés de causar outra coisa. Por exemplo, no caso do cão com o reflexo de salivar quando toca determinado som, este estímulo (um estímulo eliciador condicionado) é causa disparadora de um evento fisiológico que provoca saliva. Já a causa estruturadora do processo é a aprendizagem por pareamento à qual o cão fora submetido (isto é, o condicionamento de tipo clássico). Ele saliva, ao invés de, digamos, pular, diante do estímulo sonoro, por não ter sido os movimentos e efeitos relacionados ao pular o alvo da aprendizagem, mas sim aqueles relacionados ao de salivar. Assim, um comportamento, segundo Dretske, é um processo, determinado por causas estruturadoras, de uma causa interna produzir uma mudança corporal ou um efeito no ambiente a partir de uma causa disparadora.

A proposta de Drestke possui várias qualidades. Pois não só consegue excluir que coisas que acontecem ao organismo por simples força do ambiente externo imediato contem como comportamentos; mas também estados, ao especificar a condição de que comportamento é processo, bem como coisas que correspondem à produção de meros resultados incidentais pelo organismo, ao especificar que as variáveis envolvidas no processo são individuadas conforme as chamadas causas estruturadoras. À primeira vista, poder-se-ia acusar sua definição de incluir na extensão do definiendum a produção de resultados incidentais, posto que $C$ pode ser (por meio de mudanças corporais) causa de múltiplos efeitos no ambiente, muitos dos quais incidentais. Porém, creio que, se entendermos que a definição estabelece a condição de que as variáveis $C, M$ e $N$ relevantes são determinadas por causas estruturados, o problema é bloqueado.

Contudo, penso que a definição de Dretske enfrenta pelo menos duas dificuldades. A primeira delas é a de que se segue de sua definição que comportamento não é algo que comumente observamos. A partir dessa proposta, tem-se que quando estamos diante de um cão latindo, um pássaro pousando em uma árvore, uma pessoa cumprimentando outra com aperto de mão, etc., o que observamos são apenas sons e partes do corpo externo em movimento, e não os comportamentos desses organismos. Evidentemente, comportamentos envolvem processos causais neurofisiológicos ou afins. Além disso, há, arguivelmente, comportamentos que não transparecem na parte externa do corpo. Porém, dizemos pelo menos de muitos (provavelmente a maioria dos) comportamentos (tal como aqueles recém mencionados) que os observamos ao estarmos diante deles. É desejável preservar essa nuança da noção, exceto, quiçá, se não dispormos de uma definição mais plausível - o que, conforme sugiro em seguida, não é o caso.

A segunda dificuldade que a definição de Dretske parece enfrentar é a de acabar contando como comportamentos processos desenvolvimentais em geral, como o desenvolvimento de unhas, penas, bicos e escamas. Pois esses processos possuem causas estruturadoras (como a seleção natural, em um nível distal, e os genes do organismo, em um nível menos distal) e também coisas que se qualificam como causas disparadoras, já que eles dependem ou são influenciados por fatores tais como a nutrição e a regulação hormonal do organismo. Entretanto, conforme anteriormente apontei, pelo menos muitos processos desenvolvimentais não contam como comportamentos.

(X) A definição de Levitis et al. Em Levitis et al. (2009), a seguinte definição (disjuntiva) de comportamento é proposta: "Comportamento é: as 
respostasinternamente coordenadas (ações ou inações) dos organismos vivos inteiros ... a estímulos internos e/ou externos, excluindo respostas mais facilmente entendidas como mudanças desenvolvimentais" (p. 108). Diferentemente das definições previamente examinadas, esta pretende explicitamente abranger (i) e (iii) ao mesmo tempo; mas, como meu foco neste trabalho é em (i), não a avaliarei com respeito à sua plausibilidade quanto a (iii).

Uma possível dificuldade dessa definição é introduzir o conceito de ação (e de inação) no definiens; a saber, como sinônimo de resposta internamente coordenada do organismo vivo inteiro. Por isso, ela pode ser acusada de falhar quanto a desiderato (c). A própria introdução do conceito de resposta no definiens é problemática, pois frequentemente ele é utilizado como sinônimo de comportamento.

Porém, essa definição admite ser entendida sem circularidade. Para tanto, ela não pode pressupor a introdução do conceito de ação no definiens, bastando fazer duas coisas: primeiro, deixar de lado a equiparação entre ação (e inação) com resposta internamente coordenada do organismo vivo inteiro; e, segundo, entender o termo 'resposta' no definiens como sinônimo de algo como 'alteração no organismo' . Obtém-se, então, o enunciado de que comportamento consiste em: alterações no organismo vivo como um todo internamente coordenadas e causadas por estímulos externos ou internos, excetuando mudanças desenvolvimentais.

A expressão 'internamente coordenadas', no entanto, não é esclarecida por Levitis et al. (2009). Intuitivamente entendida, ela parece ter o papel de evitar que coisas que acontecem por simples força do ambiente externo presente contem como comportamento. Além disso, o significado intuitivo dela exclui a ideia de que qualquer coisa que um organismo faça conte como um comportamento, já que não diríamos que coisas como cair e tropeçar de modo incidental sejam coordenadas internamente. Quiçá, então, seja natural entender a referida expressão como sinônima de 'coordenadas por fatores internos ao corpo'.

Poder-se-ia julgar que a definição de Levitis et al., assim entendida, enfrenta um problema relacionado ao fato de que muitos dos movimentos feitos pelo organismo em uma caminhada ou corrida consistem em alterações coordenadas por fatores internos (neurofisiológicos). Deveria haver, no caso, mudanças desse tipo (excetuando mudanças desenvolvimentais, como querem os autores) que são provocadas por estímulos externos ou internos, mas que não contam como comportamentos. Porém, não vejo casos satisfazendo todas essas condições e, portanto, contraexemplos à proposta que questionam sua adequação com respeito ao desiderato (a).

No entanto, penso que há nela uma dificuldade com respeito ao desiderato (d); ou seja, que ela não é suficientemente informativa. Pois a definição exclui mudanças desenvolvimentais da extensão do definiendum como que por fiat. Ou seja, ela não é autoelucidativa a respeito de por que mudanças desenvolvimentais não contam como comportamentos. Como já salientado, no mínimo muitas dessas atividades deveras não merecem ser denominadas de comportamentos. Todavia, de maneira a excluí-las da extensão do definiendum, a definição em pauta apenas estabelece o critério de que as mudanças do organismo não podem ser desenvolvimentais, sem, antes, possuir um critério a partir do qual se elucidasse por que isso é o caso. Logo, pelo menos se dispormos de um critério mais básico para tanto - como julgo que sim, como já sugeri -, ela não se mostra suficientemente plausível.

(XI) A definição de Millikan. Millikan sugere a seguinte definição de comportamento:

Um comportamento é, sugiro, pelo menos o seguinte:

1. É [sic.] uma mudança ou atividade externa exibida por um organismo ou por parte externa de um organismo.

2. Ela tem uma função no sentido biológico.

3. Esta função é, ou seria normalmente, realizada via intermédio do ambiente ou via alterações resultantes na relação do organismo com o ambiente. (Millikan 1993a, p. 137)

Restringindo comportamentos ao âmbito das mudanças ou atividades externas, a condição 1 procura distinguir comportamentos de processos fisiológicos (e.g., secreções endócrinas), dado que processos fisiológicos ocorrem no interior do corpo.

A condição 2 estabelece que as mudanças ou atividades que são comportamentos são entidades que possuem funções; em particular, funções "no sentido biológico" (as quais a autora também chama 
de teleofunções ou funções próprias). O termo 'biológico' é utilizado por Millikan em um sentido alargado, podendo englobar traços que não são geralmente tidos como biológicos. Millikan (1984, 1989) tem uma teoria a respeito das funções (uma versão da teoria etiológico-histórica), mas, por questão de brevidade, não poderei me ater a ela aqui. Seja o suficiente dizer que, em linhas gerais, funções são entendidas pela autora como sendo razão de histórias seletivas envolvendo: variação entre um conjunto de entidades, algumas, em razão da posse de uma ou mais propriedades $C 1 \ldots C n$, realizando uma função $F$, enquanto outras, sem ter $C 1 \ldots C$ n, não realizando $F$; interação dessas entidades com o ambiente, aquelas que realizaram $F$ tendo um sucesso diferencial sobre aquelas que não a realizaram; e retenção das primeiras, por meio de um mecanismo de cópia e de replicação (Millikan 1984, p. 17ss; cf. também Artiga 2010, p. 198; Lazzeri 2013a). Ou seja, para utilizar a terminologia de Skinner (1981), um item possui uma função, falando de modo simplificado, se ele tem origem a partir de seleção pelas consequências de itens passados semelhantes (como ocorre, e.g., com as ocorrências de padrões operantes). Alguns itens têm funções derivadas de mecanismos que têm a função de produzi-los sob certas circunstâncias. Por exemplo, a mudança de pigmentação de um camaleão tem como uma função a de camuflagem, derivada do dispositivo de rearranjamento de pigmentação, a qual tem a função de produzir mudança de pigmentação dadas certas condições do ambiente (e.g., no caso de mudança para verde escuro, presença de vegetação verde escura) e, assim, camuflar o organismo.

Um aspecto importante da condição 2 da definição de comportamento de Millikan é que é uma condição que procura representar o caráter teleológico dos comportamentos. Essa condição exclui que a produção de coisas meramente incidentais e coisas que um organismo faça por inteira força de objetos ou eventos do meio externo imediato contem como comportamentos. O que individua o comportamento são as funções que possuem; por exemplo, no comportamento do rato de pressionar alavanca, a função de acionar liberação de alimento; no comportamento predatório do leão, funções relacionadas à obtenção da presa.

Por fim, com a condição 3, Millikan declara pretender excluir da extensão do definiendum coisas tais como o organismo excretar suor, excretar gás carbônico na atmosfera, aumentar ou diminuir a respiração em uma corrida, dentre outras, "tomadas por si mesmas" (Millikan 1993a, p. 138). Tais fenômenos são exibidos no exterior do corpo e têm funções, assim satisfazendo as condições 1 e 2 da autora; mas não são comportamentos, de modo que se faz necessário um critério para excluí-los. Não é totalmente claro o que a autora quer dizer com a condição 3, mas é bastante claro que essa condição, como a 1 , se cinge à influência de aspectos externos ao corpo.

Discordo das condições 1 e 3, apesar de, mutatis mutandis, concordar com a condição $2^{12}$. Discordo da condição 1 porque penso que a exterioridade das mudanças e atividades (tomada por si) não constitui um critério de comportamento. Desde que algo que o organismo faça no interior do corpo exemplifique os mesmos parâmetros daquilo que ele faz exteriormente e que conta como comportamento, não há por que não dizer que se trata de algo que consiste igualmente em comportamento. Sabe-se, por exemplo, que há ocorrências de reflexos, tanto incondicionados como condicionados, que se dão de tal maneira que não podemos contemplá-las pela simples observação do exterior do corpo. Esse é caso, por exemplo, da secreção de saliva pelo cão dada a presença de alimentos (como estímulos incondicionados) ou sons condicionados, dentre vários outros casos. Ou seja, esses eventos são como aqueles que podemos observar pela contemplação do que se passa no exterior do organismo e que contam como comportamentos. Tomar a internalidade deles como critério suficiente para excluí-los da extensão do definiendum falha, a meu ver, quanto ao desiderato (b). Podemos negligenciar seu caráter de comportamento meramente pelo fato de, em geral, não os vermos, ou às vezes pelo fato de ignorarmos que obedecem aos mesmos princípios causais, o que é irrelevante, ontologicamente falando ${ }^{13}$.

Há uma problema análogo ao da condição 1 com a condição 3. Pois não se deve excluir fatores internos ao corpo como podendo ser influências do

12 Isso não significa, no entanto, que concorde com pormenores da visão de Millikan sobre as ações como subclasse dos comportamentos. Sobre a perspectiva de Millikan acerca das ações, cf. Millikan (1993b).

13 É possível que essa ideia envolva uma ligeira revisão conceitual. Caso isso ocorra, trata-se de uma que considero justificada pelo argumento que acabo de oferecer. 
ambiente relevantes para comportamentos (cf., e.g., Skinner, 1953). Uma condição corporal interna (e.g., dano em algum músculo provocado por uma queda) pode funcionar como um estímulo para alguns comportamentos (e.g., comportamentos que tenham a função de amenizar o dano).

(XII) A definição de J. Moore. Segundo J. Moore (2008), comportamento é "um evento no qual uma relação causal existe entre (A) o funcionamento de um ou mais sistemas neurais ou musculares do organismo responsáveis pelo [seu] movimento ou postura (incluindo permanecer imóvel); e (B) o ambiente" (p. $66)^{14}$. O funcionamento dos referidos sistemas "pode estar em qualquer ponto ao longo de um contínuo rotulado como central ou periférico" (Moore 2008, p. 66), o que permite aparentemente evitar uma acusação (como aquela contra a definição de Dretske) de que não observamos comumente comportamentos. Outro pormenor importante é o de que Moore considera que o ambiente não é apenas o que está fora do corpo, mas também o que está dentro dele, isto é, considera que o ambiente pode corresponder a variáveis externas ou internas a ele (Moore 2008, p. 66-67). Por uma relação causal, o autor entende uma relação funcional, no sentido de uma correlação probabilística que podemos estabelecer entre variáveis referentes a (A) e a (B). Porém, Moore entende que contam como comportamentos apenas eventos que exibem relações funcionais entre (A) e (B) de certos tipos, apesar de não estabelecer isso de uma maneira explícita no definiens. $\mathrm{O}$ autor toma como relações funcionais relevantes apenas aquelas que podemos estabelecer conforme regras operacionais que permitem classificar se algo $x$ conta como ocorrência de um tipo de padrão de comportamento (Moore 2008, p. 67-68, p. 81ss). Essas regras são: (1) apresentar possíveis estímulos eliciadores, consequências reforçadoras ou punitivas, ou estímulos discriminativos; (2) verificar se processos semelhantes a $x$ ocorrem, ou tendem a ocorrer, com maior ou menor probabilidade depois disso; e, esse sendo o caso, (3) determinar se esses processos ocorrem efetivamente em razão das mudanças ambientais efetuadas em (1) ou se por outras mudanças previamente não detectadas (Moore 2008, p. 82). Essas operações permitiriam determinar ${ }_{14}$ Moore utiliza os símbolos '(a)' e (b)', ao invés de '(A)' e (B)'. Fiz a substituição de '(a)' e (b)' por '(A)' e (B)' porque utilizei os primeiros para designar os desideratos estabelecidos na seção 2. se $x$ é ocorrência, por exemplo, de um reflexo, de um padrão modal de ação ou de um operante; e, ipso facto, se se trata de um comportamento. Eventos frequentemente considerados apenas sob o ângulo fisiológico são considerados como comportamentos em determinados casos, a saber, quando se trata de eventos que possuem relações funcionais relevantes com o ambiente.

Penso que essa definição, ao ser interpretada em termos estritamente das referidas regras operacionais, não se mostra satisfatória o bastante, porque, nesse caso, falha quanto ao desiderato (a). Considere-se, por exemplo, o evento de uma pessoa cair incidentalmente. Podemos, a princípio, estabelecer uma correlação probabilística entre presença de determinados objetos no meio e determinadas mudanças no funcionamento de um ou mais sistemas neurais ou musculares do organismo responsáveis pelo movimento ou postura envolvidas na queda da pessoa. Inclusive, podemos estabelecer essa correlação em cada membro da espécie humana. Operacionalmente, isso corresponderia à ocorrência de um reflexo. Porém, como já apontei anteriormente, tais mudanças envolvidas na queda não constituem necessariamente um comportamento.

Entretanto, a definição de Moore admite ser interpretada de uma maneira alternativa e sob a qual ganha plausibilidade. Com efeito, interpretando a análise funcional como identificação da etiologia do comportamento e sem a imposição de regras operacionais muito restritivas, a definição de Moore aproxima-se daquela de Millikan. A etiologia dos comportamentos, para Moore, assim como para Millikan, jaz, em grande parte, em histórias interativas de seleção na filogênese ou ontogênese ou ambas. As mudanças ocorridas no organismo ao cair, tomadas por si, não contam como comportamento por não possuírem uma etiologia relevante. O próprio Moore, no fundo, deseja expressar isso, como transparece ao dizer:

Uma pessoa $A$ empurra a pessoa $B$, a qual cai. Quando a pessoa $B$ cai, é esse evento um comportamento? ... [O] movimento da pessoa $B$ não é comportamento. ... A queda não se desenvolve [sic.] ao longo da história da espécie ou do indivíduo .... Portanto, o sentido de comportamento relevante ... é aquele de uma interação entre o organismo e o ambiente que ... pode ter-se desenvolvido filogenético ou ontogeneticamente .... (p. 67-68) 
Se a história ontogenética e filogenética de um comportamento é considerada de maneira suficientemente distante, somos capazes de excluir da extensão do definiendum coisas que acontecem ao organismo por inteira força do ambiente externo imediado, bem como aquelas que correspondem à produção de meros resultados incidentais. As mudanças ocorridas no organismo ao cair, tomadas por si próprias, não contam como comportamento porque sua etiologia envolve meramente o ambiente externo imediato, não envolvendo seleção na filogênese ou na ontogênese. Para tomar outro exemplo, quando um animal, ao forragear, provoca sombras no solo, seu provocar as sombras não conta como comportamentos porque não se trata da produção de uma consequência reforçadora, isto é, o que ele está fazendo não é razão de ter, em algum momento em sua ontogênese, produzido sombras; e tampouco se trata de uma consequência em razão da qual o que o organismo está fazendo tenha sido selecionado filogeneticamente.

Outra modificação que considero dever ser feita na definição de Moore de maneira a se tornar plausível é tirar do definiens a menção a tipos específicos de substratos responsáveis pelos movimentos e a postura do organismo, posto que do contrário não engloba comportamentos de seres vivos que não possuem neurônios ou músculos. Mais do que isso, sugiro que não seja feita menção a substratos responsáveis por movimentos e postura do organismo. Um critério que acredito manter as atividades desenvolvimentais e os eventos fisiológicos que não contam como comportamentos (e.g., desenvolvimento de dentes, escamas, penas e bicos; processes fisiológicos como o batimento regular do coração, a respiração regular, a transformação dos alimentos no estômago) fora da extensão do conceito é (como já salientei antes) o de que os eventos ambientais aos quais Moore se refere com (B) sejam eventos que afetem sensorialmente o organismo, seja em seu exterior (como estímulos exteroceptivos) ou em seu interior (como estímulos proprioceptivos ou interoceptivos).

\section{DUAS DEFINIÇÕES DE COMPORTAMENTO}

Concluo propondo (com apoio em minha argumentação nas seções anteriores) duas definições de comportamento. Não afirmo que elas sejam inteiramente satisfatórias (elas podem eventualmente ser aprimoradas), mas sugiro que são as mais plausíveis em comparação com as outras definições que encontrei na literatura relevante. São formulações baseadas, respectivamente, nas de Millikan e de Moore. A primeira definição que proponho é a seguinte:

(D.1) Comportamento é aquilo que um organismo faz que possui uma ou mais funções (que devem ser entendidas, resumidamente falando, em termos de histórias de seleção filogenética ou ontogenética) e cuja etiologia envolve parcialmente fatores do ambiente presente como estímulos sensoriais.

A segunda definição que proponho é a seguinte:

(D.2) Comportamento é aquilo que um organismo faz cuja etiologia envolve (em parte) processos seletivos na filogênese ou na ontogênese do organismo e (em parte) fatores do ambiente presente atuando como estímulos sensoriais.

(D.2) expressa um conteúdo similar a (D.1), diferindo em não fazer uso explícito do conceito de função. Antes, (D.2) substitui a terminologia de funções pela de histórias ontogenéticas ou filogenéticas do organismo, em termos da qual funções são entendidas em (D1)

\section{REFERÊNCIAS}

Allen, C., \& Bekoff, M. (1997). Species of mind. Cambridge: MIT Press.

Artiga, M. (2010). Learning and selection processes. Theoria, 25, 197-208.

Bergner, R. M. (2011). What is behavior? And so what? New Ideas in Psychology, 29, 147-155.

Block, N. (1978). Troubles with functionalism. Em C. W. Savage (Ed.), Minnesota studies in the philosophy of science: Vol. 9 (pp.261-325). Minneapolis: University of Minnesota Press.

Bunge, M., \& Ardila, R. (1987). Philosophy of psychology. New York: Springer.

Burgess, J.A. (2008). When is circularity in definitions benign? Philosophical Quarterly, 58, 214-233. 
Chance, P. (2003). Learning \& behavior ( $5^{\text {th }}$ ed.). Belmont: Wadsworth.

Cooper, D. E. (1972). Definitions and 'clusters'. Mind, new series, 81, 495-503.

Copi, I. M. (1982). Introduction to logic ( $6^{\text {th }}$ ed.). New York: Macmillan.

Davis, D. E. (1966). Integral animal behavior. New York: Macmillan.

Donahoe, J. W., \& Palmer, D. C. (1994). Learning and complex behavior. Boston Allyn \& Bacon.

Dretske, F. (1988). Explaining behavior: Reasons in a world of causes. Cambridge: MIT Press.

Goldberg, S., \& Pessin, A. (1997). Gray matters: An introduction to the philosophy of mind. New York: M. E. Sharpe.

Hornsby, J. (2006/1986). Physicalist thinking and conceptions of behaviour. Em J. Bermúdez (Ed.), Philosophy of psychology: Contemporary readings (pp.31-47). London: Routledge.

Jessor, R. (1958). The problem of reductionism in psychology. Psychological Review, 65, 170-178.

Kenny, A. (2003). Action, emotion and will. London: Routledge. (Obra original publicada em 1963)

Lazzeri, F. (2013a). Observações sobre o behaviorismo teleológico: Parte 2. Acta Comportamentalia, 21, 391-408.

Lazzeri, F. (2013b). Referir-se-ão as categorias psicológicas ordinárias a causas internas do comportamento? Philósophos, 18, 41-73.

Lazzeri, F. (2014). A conceptual difficulty with some definitions of behavior. Em Tópicos de filosofia contemporânea. Anais do $8^{\circ}$ Simpósio Internacional Principia.

Lazzeri, F. (No prelo 1). On defining behavior: Some conceptual preliminaries. Behavior and Philosophy.

Lazzeri, F. (No prelo 2). Dynamic interactions with the environment make up our psychological phenomena: A review of Noë's Out of our heards. The Psychological Record.

Lazzeri, F. (No prelo 3). On the place of behavior in the analysis of psychological categories.
Lee, V. L. (1983). Behavior as a constituent of conduct. Behaviorism, 11, 199-224.

Lehner, P. N. (1996). Handbook of ethologicalmethods ( $2^{\text {nd }}$ ed.). Cambridge: Cambridge University Press.

Levitis, D. A., Lidicker Jr., W. Z., \& Freund, G. (2009). Behavioural biologists do not agree on what constitutes behaviour. Animal Behaviour, 78, $103-110$.

Lewis, D. K. (1974). Radical interpretation. Synthese, $23,331-344$.

Marken, R. (1982). Intentional and accidental behavior: A control theory analysis. Psychological Reports, 50, 647-650.

Maturana,H. R. (1995). Biology of self-consciousness. Em G. Tratteur (Ed.). Consciousness: Distinction and reflection (pp.145-175). Naples: Bibliopolis.

Mele, A. R. \& Moser, P. K. (1994). Intentional action. Noûs, 28, 39-68.

Millikan, R. G. (1984). Language, thought, and other biological categories: New foundations for realism. Cambridge: MIT Press.

Millikan, R. G. (1989) In defense of proper functions. Philosophy of Science, 56, 288-302.

Millikan, R. G. (1993a). What is behavior? A philosophical essay on ethology and individualism in psychology, Part 1. In White queen psychology and other essays for Alice (pp.135-150). Cambridge: MIT Press.

Millikan, R. G. (1993b). The green grass growing all around: A philosophical essay on ethology and individualism in psychology, Part 2. In White queen psychology and other essays for Alice (pp.151-170). Cambridge: MIT Press.

Moore, J. (2008). Conceptual foundations of radical behaviorism. Cornwall-on-Hudson: Sloan.

Myers, D. G. (2010). Psychology (9 $9^{\text {th }}$ ed.). New York: Worth Publishers.

Pacherie, E. (2011). Framing joint action. Review of Philosophy and Psychology, 2, 173-192.

Pierce, W. D., \& Cheney, C. D. (2004). Behavior analysis and learning ( $3^{\text {rd }}$ ed. $)$. Mahwah: Lawrence Erlbaum. 
Powell, R. A., Symbaluck, D. G., \& Honey, P. L. (2009). Introduction to learning and behavior ( $3^{\text {rd }}$ ed.). Belmont: Wadsworth.

Rosenblueth, A., Wiener, N., \& Bigelow, J. (1943). Behavior, purpose and teleology. Philosophy of Science, 10, 18-24.

Searle, J. R. (2002/1990). Collective intentions and actions. In Consciousness and language (pp.90105). Cambridge: Cambridge University Press.

Skinner, B. F. (1938). The behavior of organisms. New York: Appleton-Century-Crofts.

Skinner, B. F. (1953). Science and human behavior. New York: Macmillan.

Skinner, B. F. (1981). Selection by consequences. Science, new series, 213 (4507), 501-504.

Solomon, E. P., Berg, L. R., \& Martin, D. W. (2008). Biology ( $8^{\text {th }}$ ed.). Belmont: Thomson.

Taylor, C. (1964). The explanation of behaviour. London: Routledge.

Tinbergen, N. (1951). The study of instinct. Oxford: Oxford University Press.

Todorov, J. C. (2012). Sobre uma definição de comportamento. Perspectivas em Análise do Comportamento, 3, 32-37.

Tolman, E. C. (1932). Purposive behavior in animals and men. New York: Appleton-Century-Crofts.

Watson, J. B. (1919). Psychology: From the standpoint of a behaviorist. Philadelphia: Lippincott.

Watson, J. B. (1930). Behaviorism ( $2^{\text {nd }}$ ed.). Chicago: University of Chicago Press.

Watson, S. T., \& Brown, D. (2011). Behavior. Em S. Goldstein \& J. A. Naglieri (Eds.), Encyclopedia of child behavior and development: Volume 1, A-D (pp.221-222). New York: Springer.

White, A. R. (1968). Introduction. In A. White (Ed.), The philosophy of action (pp.1-18). Oxford: Oxford University Press.

Wittgenstein, L. (1953). Philosophical investigations. (G. E. Anscombe, Trans.). Oxford: Blackwell.

Wright, L. (1976). Teleological explanations: An etiological analysis of goals and functions. Berkeley: University of California Press. 